\title{
Phytoconstituent Analysis Using Modern Analytical Techniques
}

\section{Pankaj Gupta*}

School of Medical and Allied Sciences, KR Mangalam University, Gurgaon, Haryana, India

\section{Editorial}

Finding newer drugs is an inevitable part of the drug discovery process and nature has proven to be an invincible source for this purpose. Phytoconstituent anaylsis has always been an integral part of drug discovery process for finding newer molecules with therapeutic efficacy that can be used for the treatment of various diseases and ailments. The lead of such compounds may come from the available traditional knowledge or by the randomized pharmacological or biological screening of the crude drug extracts.

Phytoconstituent analysis involves usage of various analytical techniques for the isolation and characterization of phytoconstituents. Primitive techniques basically involved usage of column chromatography for the purpose of isolation of phytoconstituents wherein silica used to act as stationary phase and mobile phases ranges non-polar to polar solvents. Though this technique was highly beneficial but had several drawbacks such as longer time periods and isolates obtained were not highly purified. Later on, flash chromatography was introduced wherein pressurized gas was used to drive the solvent through the column of stationary phase resulting in a rapid and high resolution chromatography.

However, today modern analytical techniques have been introduced that are highly advanced and offer precise and highly purified separation of phytoconstituents in a shorter period of time. These techniques include semi-preparative and preparative high performance liquid chromatographic systems. The modern semi-preparative HPLC enables the users to isolate $\mu \mathrm{g}$ quantities of plant components by using binary gradient mode while preparative HPLC ensures optimum isolation of phytochemicals at preparative scale. As the phytoconstituents are present in very low quantities in plants, these techniques are highly beneficial for isolating the phytoconstituents in larger quantities and in relatively lesser periods of time.
*Corresponding author: Dr. Pankaj Gupta, Assistant Professor, School of Medical and Allied Sciences, KR Mangalam University, Sohna Road, Gurgaon-122 103, Haryana, India, Tel: +91119818256122; E-mail: gupta.aiims@gmail.com

Received March 06, 2017; Accepted March 09, 2017; Published March 13, 2017

Citation: Gupta P (2017) Phytoconstituent Analysis Using Modern Analytical Techniques. Nat Prod Chem Res 5: e119. doi: 10.4172/2329-6836.1000e119

Copyright: @ 2017 Gupta P. This is an open-access article distributed under the terms of the Creative Commons Attribution License, which permits unrestricted use, distribution, and reproduction in any medium, provided the original author and source are credited. 